\title{
REVIEW
}

\section{ROLE OF VITAMIN D AND ADIPOSE TISSUE HORMONES IN WOMEN WITH REPRODUCTIVE DISORDERS}

Presiyana V. Nyagolova*, Mitko D. Mitkov, Maria M. Orbetsova

Second Department of Internal Medicine, Department of Endocrinology, Medical Faculty, Medical University, Plovdiv, Bulgaria

\section{РОЛЬ ВИТАМИНА D И ГОРМОНОВ ЖИРОВОЙ ТКАНИ У ЖЕНЩИН С НАРУШЕ- НИЯМИ РЕПРОДУКТИВНОЙ ФУНКЦИИ}

\author{
Вторая кафедра внутренних болезней, Секиия эндокринологии, Факультет Медииины, Медииинский \\ университет - Пловдив, Болгария
}

\begin{abstract}
The role of vitamin D beyond that it plays in bone metabolism and calcium homeostasis has been lately quite emphasized. In this respect, vitamin D deficiency has been associated with higher risk of cardiovascular disease, metabolic syndrome, and reproductive disorders. Growing evidence has suggested that vitamin D deficiency is implicated in the pathogenesis of insulin resistance and the development of metabolic disorders in the polycystic ovary syndrome. The goal of the review is to present contemporary concepts of the relationship between hormones affecting the metabolic body status, serum vitamin D levels and the reproductive function.
\end{abstract}

Key words: reproductive function, adipocytokines, neuropeptides, vitamin D

Folia Medica 2015; 57(1): 5-10

Copyright (C) 2015 Medical University, Plovdiv

\section{РЕЗЮМЕ}

В последние годы особое внимание уделяется роли витамина D в обмене веществ костной ткани и кальциевого гомеостаза. В этом контексте дефицит витамина D связывается с повышением риска сердечно-сосудистых заболеваний, метаболического синдрома и нарушений репродуктивной функции. Накапливаются данные о том, что дефицит витамина D участвует в патогенезе инсулинорезистентности и в развитии метаболических нарушений в случаях синдрома поликистозных яичников. Цель настоящего обзора состоит в том, чтобы представить современные взгляды на взаимосвязь между гормонами, связанными с метаболическим состоянием организма, уровнями сывороточного витамина $\mathrm{D}$ и репродуктивной функцией.

Ключевые слова: репродуктивная функиия, адипоиитокины, нейропептиды, витамин $D$

Folia Medica 2015; 57(1): 5-10

(C) 2015 Все права защищены. Медицинский университет, Пловдив

\section{INTRODUCTION}

Vitamin D and its active metabolite - 1,25(OH)2D3 (calcitriol) - have a major role in calcium and phosphorus metabolism. The vitamin itself is considered to be a pre-hormone, whose activation in the liver and the kidneys is carried out along several biochemical pathways. Vitamin D stimulates calcium absorption in the small intestine and enhances calcium reabsorption in the kidneys. Another key point in its action is its involvement in bone formation and remodelling. The role of vitamin $\mathrm{D}$ beyond bone metabolism and calcium homeostasis has been emphasised in recent years. There is a growing body of evidence that suggests that vitamin D deficiency is involved in the pathogenesis of several reproductive diseases, the best studied of which is polycystic ovary syndrome (PCOS).

PCOS is one of the most common endocrinopathies, affecting 8 to $14 \%$ of women in reproductive age. ${ }^{1}$ Its classic manifestation is characterized by the triad: oligo-/anovulation, hyperandrogenism and polycystic ovarian morphology. According to most 
researchers overweight and obesity are observed in $30-80 \%$ of women with the syndrome ${ }^{2}$, and frequency varies widely between different nationalities. PCOS is currently seen as the prototype of the sex-specific metabolic syndrome. It is associated with risk factors for cardiovascular diseases, metabolic syndrome and/or its individual components - hypertension, dyslipidemia, atherosclerosis, impaired glucose tolerance/diabetes mellitus, even some hormone-dependent forms of malignancies in women. In women with PCOS, insulin resistance has been found to correlate strongly with reproductive disorders but it is very often that vitamin D deficiency is also detected in such patients.

The objective of this review is to present contemporary concepts of the relationship between hormones affected by the body metabolic status, serum vitamin D levels, and reproductive function.

\section{VITAMIN D DEFICIENCY}

The most common categorization of serum $25(\mathrm{OH})$ vitamin D levels in adults is as follows: $>75 \mathrm{nmol} / \mathrm{L}$ $(>30 \mathrm{ng} / \mathrm{mL}$ ) for vitamin D sufficiency, 50-70 $\mathrm{nmol} / \mathrm{L}(20-28 \mathrm{ng} / \mathrm{mL})$ for insufficiency and $<50$ $\mathrm{nmol} / \mathrm{L}(<20 \mathrm{ng} / \mathrm{mL})$ for vitamin D deficiency.

It has been estimated that 1 billion people worldwide have vitamin D deficiency or insufficiency. ${ }^{3}$ Moreover, $40-100 \%$ of adults in the United States and the European countries have vitamin D deficiency, since aging is associated with a reduction in the concentration of 7-dehydrocholesterol in the skin. Obesity is also a risk factor for vitamin D deficiency. Low hormone levels among older people and people with obesity may be the result of decreased physical activity outdoors and minimal exposure to sunlight. There is increased risk in racial and ethnic groups with darker skin living in the northern hemisphere, as the skin pigment melanin absorbs UV radiation and thereby decreases the synthesis of vitamin D. Children and adolescents, pregnant and lactating women (especially multiparous ones) with short intervals between pregnancies and dark skin, are potentially at high risk of vitamin D deficiency. ${ }^{4}$ In previous studies in 2008 we demonstrated that vitamin D deficiency and insufficiency was found in over $80 \%$ of randomly selected elderly Bulgarian women. In patients with type 2 diabetes mellitus and insulin resistance, deficiency frequency is, on average, twice as high as that in the general Bulgarian population. ${ }^{5,6}$

\section{VITAMIN D - STRUCTURE AND DISTRIBUTION}

The predominant source of vitamin $\mathrm{D}$ is the endogenous cutaneous synthesis while food sources contribute up to $20 \%$ of its circulating levels. Endogenous synthesis of vitamin D (cholecalciferol or D3) takes place after photolytical conversion of 7-dehydrocholesterol, localized in dermal fibroblasts and epidermal keratinocytes, with the aid of ultraviolet B-component of solar light (wavelength, 280 $\mathrm{nm}$ and $315 \mathrm{~nm}) .{ }^{7}$ Circulating vitamin D-prohormone (taken with food or endogenously synthesized) is metabolized using a range of cytochrome P450 enzymes; liver 25-hydroxylase (CYP27A1) converts the prohormone to an intermediate metabolite (25-hydroxy vitamin D), while 1-alpha hydroxylase (CYP27B1) generates the metabolically active form - 1,25-dihydroxy vitamin $D$, predominantly in the kidneys. ${ }^{8}$

Vitamin D belongs to the family of steroid hormones. Cellular effects of the hormone and its metabolites are primarily mediated by the intracellular vitamin D receptor (VDR), which belongs to the family of nuclear hormone receptors. VDR is expressed in various tissues, including the intestines, parathyroid glands, immune cells, as well as the components of the hypothalamic-pituitary axis and the reproductive tract. ${ }^{9}$ Presence of VDR in the ovaries, uterus, placenta and testes suggests a regulatory role of vitamin $\mathrm{D}$ in the physiology of reproductive processes.

More recent evidence suggests an additional mechanism of signalling through the membraneassociated steroid binding receptor of the rapid response (MARRS, also known as Erp57/Grp58). Presence of such a mechanism is presumed in various tissues, including the intestines, bones, parathyroid glands, liver, monocytes and pancreatic beta cells. ${ }^{7}$ That pathway of signalling, however, is not fully understood. Signalling through VDR is also associated with the gene expression of CYP19 (aromatase) which functionally relates vitamin D to the reproductive steroid hormones family. ${ }^{10}$

Circulating vitamin D metabolites are associated with different serum proteins, the most important being the vitamin D-binding protein (DBP) which is synthesized in the liver. Except as a transport protein, DBP according to some authors, plays an active role in the action of vitamin D. Due to its relatively high capacity of binding to $25(\mathrm{OH}) \mathrm{D} 3$, DBP is most likely determinative for the presence of a substrate for 1-alpha-hydroxylase. ${ }^{11}$ 


\section{INSULIN RESISTANCE AND VITAMIN D}

The mechanism of selective accumulation of visceral fat is not fully clarified. In people with visceral obesity availability of $\beta-3$ adrenoceptors in omentum adipocytes is proved as these receptors show increased sensitivity to lipolytic stimuli. Upon fasting intensified lipolysis increases the concentration of free fatty acids (FFA) into the portal vein. When entering the liver they increase the production of lipoproteins with very low density (VLDL) and potentiate the gluconeogenesis. This results in hyperlipoproteinemia, reduced glucose tolerance and hyperinsulinemia, and hence - insulin resistance.

Evidence is accumulating that through this mechanism vitamin D deficiency is involved in the pathogenesis of insulin resistance and metabolic syndrome in PCOS. ${ }^{12}$ Various authors suggest a role of the hormone in the function of pancreatic beta cells. It affects glucose-dependent insulin secretion directly and indirectly, but does not seem to affect the basal insulinemia. Direct effects of vitamin D are mediated by binding of the active metabolite $(1,25(\mathrm{OH}) 2 \mathrm{D} 3)$ with VDR of the beta cells. It is possible that activation of vitamin $\mathrm{D}$ in beta-cells is helped by 1-alpha-hydroxylase, expressed there. Indirect effects are associated with the regulation of calcium beta-cell influx, since insulin secretion is calcium-dependent. ${ }^{13}$ Therefore, changes in calcium flux may have adverse effects on beta-cell secretory function, particularly in response to glucose load. Vitamin D is essential for insulin secretion and restoration of its levels after replacement therapy improves insulin sensitivity. ${ }^{14}$

Fluctuations in intracellular calcium levels in insulin-dependent tissues such as skeletal muscles and adipose tissue may contribute to the development of peripheral insulin resistance. This is done by down-regulation of insulin receptors, decreased sensitivity of insulin-dependent enzymes such as lipoprotein lipase or impaired insulin signal transduction, leading to a reduction in the activity of Glucose Transporter Type 4 (GLUT-4). In the peripheral insulin-dependent tissues vitamin D may improve insulin sensitivity by stimulation of insulin receptors expression. ${ }^{15}$

Despite such data supporting the role of vitamin $\mathrm{D}$ in the development of type 2 diabetes, it is unlikely that hormone deficiency is the main cause of the disease. Further studies are needed to support this hypothesis.

Recent studies found inverse correlation between serum levels of $25(\mathrm{OH}) \mathrm{D} 3$ and insulin resistance, hyper-androgenism and circulating androgens in women with PCOS. ${ }^{16}$ Replacement therapy with vitamin D results in normalization of the menstrual cycle in such patients, improvement in insulin sensitivity and reduction of circulating androgens. ${ }^{17}$ The components of metabolic syndrome in PCOS are associated with vitamin D insufficiency ${ }^{18}$, thereby suggesting that this is the basis of the pathogenesis of PCOS. It is difficult to determine, however, whether this deficiency contributes alone to the development of the syndrome, since a great part of women with PCOS is obese or overweight.

\section{ADIPOSE TISSUE HORMONES AND NEUROEN- DOCRINE BASES OF THE METABOLIC STATUS OF THE BODY}

Contemporary concepts of the regulation of female hypothalamic-pituitary-gonadal (HPG) axis in general and the neuroendocrine control of ovulation in particular are associated with kisspeptin and its receptor GPR54. Kisspeptin is a key intermediary in relaying energy balance related information to the centers regulating the gonadotrophin axis. It also contributes to connecting reproductive capacity to the energy balance and the metabolic status. In women the HPG axis has some specific characteristics in terms of functionality. This includes the generation of pre-ovulatory peak of gonadotropins as hormonal onset of ovulation - a complex neuroendocrine phenomenon, highly sensitive to various exo- and endogenous factors. These trigger a cascade of events, such as pre-ovulatory rise in estradiol secretion by the dominant follicle of the ovary, followed by reduction of the hypothalamic GnRH release. ${ }^{19}$ The actual role of kisspeptin in humans needs to be further clarified.

Several series of evidence lead to the hypothesis that Kiss 1 neurons in the forebrain act as sensors of altered energy balance and metabolic disorders. ${ }^{20}$ The hypothalamic Kiss1 system has been demonstrated to be sensitive to the metabolic status of the body, but the question that arises from these observations is which neuroendocrine signals are responsible for transmitting such metabolic information to Kiss 1 neurons. Although this question is yet to find a comprehensive answer, it is believed that leptin plays a dominant role.

The central role of kisspeptins and GPR54 in controlling GnRH and hence the HPG axis stimulates analysis of the potential function of this system in mediating the effects of already known regulators of the reproductive axis such as insulin, ghrelin, adiponectin, leptin.

Visceral adipose tissue produces several media- 
tors (hormones and cytokines) that affect the insulin action in skeletal muscles. Excessive adipose tissue is associated with reduced production of the antiatherogenic and increased production of atherogenic adipocytokines.

Leptin is the major protein secreted by adipocytes - its discovery confirmed the role of adipose tissue as the largest endocrine organ in the human body. Involvement of this hormone in the regulation of body weight has already been demonstrated, as well as the deposition of fats in fat depots - its plasma levels closely correlate with Body Mass Index (BMI) and adipose tissue quantities. In a previous study we found higher levels of leptin in women with PCOS with borderline significance compared with healthy controls matched in age, weight, BMI, waist circumference and the waist to hips ratio (WHR). Significant dependence of leptin has been found both with BMI and the WHR, as well as with basal insulin and HOMA-index in the pathology group. ${ }^{21}$ Apparently, leptin co-participates in the pathogenesis of PCOS, primarily in insulin resistance and obese bearers of the syndrome, but its role remains to be elucidated. From the data accumulated so far it seems that leptin interacts in the brain with almost all known neuropeptides included in the regulation of energy balance and food intake. Leptin plays an essential role in the metabolic control of reproductive function. It is the main signal of energy accumulation, which stimulates and facilitates activation of $\mathrm{GnRH}$ neurons.

Evidence is accumulating in support of a neuroendocrine leptin-kisspeptin-GnRH pathway, where sufficient levels of leptin, acting through Kiss1 neurons, provide proper maturation and function of GnRH neurons and respectively, of the hypothalamic-pituitary-gonadal axis. ${ }^{22}$ This pathway may help to explain the pathophysiological bases of a large number of reproductive disorders, related to energy shortage as anorexia nervosa, extreme physical exertion, underweight or overweight.

Leptin levels vary during the menstrual cycle, with a sharp increase during the luteal phase. Varying concentrations during estrogen cycle and pubertal development and its association with $\mathrm{LH}$ secretion suggests that it plays a central role in the metabolic control of the neuroendocrine regulation of reproductive function. ${ }^{23}$

Several studies indicate that ghrelin has an important role in the regulation of glucose homeostasis and insulin release regardless of the secretion of growth hormone. Lower plasma levels of ghrelin are associated with an increase of basal insulin and insulin resistance, suggesting that this peptide plays a physiological and pathophysiological role in carbohydrate metabolism. Very recent studies have found abnormalities in ghrelin regulation in PCOS that are not characteristic only for the disease-specific obesity and insulin resistance. The underlying mechanisms of this dysregulation and the role of ghrelin in reproductive processes need further clarification. ${ }^{24}$ Ghrelin, like leptin, seems to be a key factor, linking energy balance and reproductive function in men and women. The data so far show its intervention in the regulation of fertility.

Insulin is also involved in the integration of metabolism and the reproduction process. It is an anabolic hormone involved in the maintenance of energy balance and normal body weight. ${ }^{25}$ Secreted in response to food intake, insulin acts on its key tissues (skeletal muscles, liver, adipose tissue) by stimulating the accumulation of energy mainly in the form of glycogen and fat. Although plasma insulin levels vary periodically, basal levels are proportional to the amount of fatty tissue. Since this stable state of insulin affects the energy reserves, circulating insulin levels seem to transmit information about the long-term metabolic status to the reproductive axis. Insulin regulates $\mathrm{GnRH}$ and Luteinizing Hormone (LH) secretion. Insulin resistance is present in obesity, which violates insulin action. Pulsatile LH secretion is suppressed in cases of insulin deficiency (such as starvation or diabetes), and the central administration of insulin can restore LH deficiency in these conditions.

Recent studies have shown that adipose tissue produces prolactin, besides expressing its receptor. These studies highlight the role of prolactin as a cytokine involved in the function of adipose tissue. Biologically active prolactin is released by all fat depots: thoracic, visceral and subcutaneous adipose tissue. Its expression is regulated by non-pituitary, peripheral regulators. Its release is enhanced during early adipocyte differentiation and is stimulated by cyclic Adenosine Monophosphate (AMP) activators, including beta-adrenergic receptor agonists. Several lines of evidence indicate that prolactin inhibits lipid accumulation as well as the release of adipocytokines as adiponectin, interleukin- 6 and, possibly, leptin. It is also involved in the regulation of adipogenesis. These studies suggest the role for prolactin in energy homeostasis through its actions as adipocytokine and participation in the pathogenesis of insulin resistance. ${ }^{26}$

It is now clear that fertility is closely linked to 
the metabolic status of the body, but cellular and molecular mechanisms that represent the relationship between energy reserves and reproduction are not yet fully understood. The greater the number of identified adipokines, neuropeptides and peptides of the gastrointestinal tract included in energy homeostasis, the greater the number of potential connections between the energy status and HPG axis.

Accumulated data for the involvement of vitamin $\mathrm{D}$ in insulin resistance development suggest connection of the hormone with certain mediators which link the metabolism to the neuroendocrine reproductive system and thus regulate reproductive activity as a function of the energy status.

\section{CONCLUSIONS}

Reproductive disorders represent currently a challenge for researchers, for despite the intense interest of many research teams around the world, a number of issues still remain unresolved - inheritance, etiology and pathogenesis, precise mechanisms of insulin resistance development, role of adipose tissue hormones and neuroendocrine bases of the metabolic status of the organism, role of vitamin D outside bone biology. Additional research in this area to refine the role of various peripheral metabolic signals on the activation and maintenance of gonadotrophin axis would make possible their future use in the treatment of reproductive disorders.

\section{REFERENCES}

1. Norman RJ, Wu R, Stankiewicz MT. Polycystic ovary syndrome. Med J Aust 2004;180(3):132-7.

2. Bates GW, Legro RS. Long-term management of Polycystic Ovarian Syndrome (PCOS). Mol Cell Endocrinol 2013;373(1-2):91-7.

3. Holick MF. Vitamin D deficiency. N Engl J Med 2007;357(3):266-81.

4. Pearce SH, Cheetham TD. Diagnosis and management of vitamin D deficiency. BMJ 2010;340:b5664.

5. Bakalov D, Boyanov M, Tsakova A, Grozeva V, Mekova R. Prevalence of deficiency and insufficiency of vitamin $\mathrm{D}$ in patients with type 2 diabetes mellitus on oral antidiabetic drugs. Endocrinologia 2013;18:19-26 (Bulgarian).

6. Borisova AM, Shinkov A, Vlahov J, et al. Frequency of deficiency, insufficiency and sufficiency of vitamin D in 20-80-year-old Bulgarian population. Endocrinologia 2012;3:122-34 (Bulgarian).

7. Ashwell M, Stone EM, Stolte H, Cashman KD, Macdonald H, Lanham-New S, et al. UK Food Standards Agency Workshop Report: an investigation of the relative contributions of diet and sunlight to vitamin D status. Br J Nutr 2010;104 (4):603-11.
8. Schuster I. Cytochromes P450 are essential players in the vitamin D signaling system. Biochim Biophys Acta 2011;1814:186-99.

9. Christakos S, Dhawan P, Benn B, Porta A, Hediger M, Oh G.T, et al. Vitamin D: molecular mechanism of action. Ann N Y Acad Sci 2007;1116:340-8.

10. Christakos S, Barletta F, Huening M, Dhawan P, Liu Y, Porta A, Peng X. Vitamin D target proteins: function and regulation. J Cell Biochem 2003;88(2):238-44.

11. Nykjaer A, Dragun D, Walther D, Vorum H, Jacobsen $\mathrm{C}$, Herz J, et al. An endocytic pathway essential for renal uptake and activation of the steroid $25(\mathrm{OH})$ vitamin D3. Cell 1999;96(4):507-15.

12.Ngo DT, Chan WP, Rajendran S, Heresztyn T, Amarasekera A, Sverdlov AL, et al. Determinants of insulin responsiveness in young women: impact of polycystic ovarian syndrome, nitric oxide, and vitamin D. Nitric Oxide 2011;25(3):326-30.

13. Van Belle TL, Gysemans C, Mathieu C. Vitamin D and diabetes: the odd couple. Trends Endocrinol Metab 2013;24(11):561-8.

14. Borissova AM, Tankova T, Kirilov G, Dakovska L, Kovacheva R. The effect of vitamin D3 on insulin secretion and peripheral insulin sensitivity in type 2 diabetic patients. Int J Clin Pract 2003;57:258-61.

15. Maestro B, Campión J, Dávila N, Calle C. Stimulation by 1,25-dihydroxyvitamin D3 of insulin receptor expression and insulin responsiveness for glucose transport in U-937 human promonocytic cells. Endocr J 2000;47(4):383-91.

16. Mahmoudi T, Gourabi H, Ashrafi M, Yazdi RS, Ezabadi Z. Calciotropic hormones, insulin resistance, and the polycystic ovary syndrome. Fertil Steril 2010;93(4):1208-14.

17.Pal L, Berry A, Coraluzzi L, Kustan E, Danton C, Shaw J. Therapeutic implications of vitamin D and calcium in overweight women with polycystic ovary syndrome. Gynecol Endocrinol 2012;28(12):965-8.

18. Foss YJ. Vitamin D deficiency is the cause of common obesity. Med Hypotheses 2009;72(3):314-21.

19. Schwartz NB. Neuroendocrine regulation of reproductive cyclicity. In: Conn MP, Freeman ME, eds. Neuroendocrinology in Physiology and Medicine. Part II. Oregon: Humana Press;2000:135-45.

20. Wahaba F, Atikaa B, Shahaba M. Kisspeptin as a link between metabolism and reproduction: Evidences from rodent and primate studies. Metabolism 2013;62(7):898-910.

21. Orbetsova M. Adipose tissue hormones in women with polycystic ovary syndrome: literature review with own data. Science Endocrinology 2009;6:25861 (Bulgarian).

22. Hausman GJ, Barb CR, Lents CA. Leptin and reproductive function. Biochimie 2012; 94(10):2075-81.

23. Ahrens K, Mumford SL, Schliep KC, Kissell KA, 
Perkins NJ, Wactawski-Wende J, et al. Serum leptin levels and reproductive function during the menstrual cycle. Am J Obstet Gynecol 2014;210:248e1-9.

24. Orbetsova M, Mitkov M, Pehlivanov B. Ghrelin - its role in the regulation of body weight, metabolic and reproductive disorders. Endocrinology 2010;4:21223 (Bulgarian).
25.Kanzaki M, Pessin JE. Signal integration and the specificity of insulin action. Cell Biochem Biophys 2001;35:191-209.

26. Brandebourg T, Hugo E, Ben-Jonathan N. Adipocyte prolactin: regulation of release and putative functions. Diabetes Obes Metab 2007;9:464-76. 